\title{
DIGITALCOMMONS
}

@WAYNESTATE-

Wayne State University

\section{A Preliminary Study Interrogating the Cataloging and Classification Schemes of a K-12 Book Discovery Platform through a Critical Race Theory Lens}

\author{
Kafi D. Kumasi \\ Wayne State University, ak4901@wayne.edu \\ Cynthia Jimes \\ Institute for the Study of Knowledge Management in Education \\ Amee Evans Godwin \\ Institute for the Study of Knowledge Management in Education \\ Lisa A. Petrides \\ Institute for the Study of Knowledge Management in Education \\ Anastasia Karaglani \\ Institute for the Study of Knowledge Management in Education
}

Follow this and additional works at: https://digitalcommons.wayne.edu/slisfrp

Part of the Cataloging and Metadata Commons, and the Race and Ethnicity Commons

\section{Recommended Citation \\ Kumasi, K. D., Jimes, C., Godwin, A. E., Petrides, L. A., \& Karaglani, A. (2020). A preliminary study interrogating the cataloging and classification schemes of a K-12 book discovery platform through a critical race theory lens. Open Information Science, 4(1), 106-121. doi: 10.1515/opis-2020-0009}

This Article is brought to you for free and open access by the School of Information Sciences at DigitalCommons@WayneState. It has been accepted for inclusion in School of Information Sciences Faculty Research Publications by an authorized administrator of DigitalCommons@WayneState. 


\title{
Research Article
}

Kafi D. Kumasi*, Cynthia Jimes, Amee Evans Godwin, Lisa A. Petrides, Anastasia Karaglani

\section{A Preliminary Study Interrogating the Cataloging and Classification Schemes of a K-12 Book Discovery Platform through a Critical Race Theory Lens}

https://doi.org/10.1515/opis-2020-0009

Received December 6, 2019; accepted June 30, 2020

\begin{abstract}
This article presents the results of a preliminary study to examine the cataloging and classification schemes and ideological factors that play out in book discovery platforms for children's and young adult books. Using Critical Race Theory and a Rapid Contextual Design approach to exploring the curatorial behaviors of school librarians when searching for diverse books, the study offers design ideas for retooling discovery platforms in ways that bridge the cultural disconnect that young adults from historically marginalized racial backgrounds experience in their libraries. The article concludes that in order for school librarians to find, recommend and teach about books that reflect race, equity and inclusion themes, they need more sophisticated and user-centered features that reflect critical race and multicultural analytic frameworks. This includes the need for a common vocabulary around issues of race, equity and inclusion that can simultaneously cut through the ambiguity of social tagging and yet subvert the status quo of entrenched liberalism and/or racially biased ideologies embedded in traditional classification schemes and hierarchies, such as those used in Library of Congress subject headings. The findings further suggest that school librarians would benefit from enhanced education and training in the intersections of cataloging, classification and critical race scholarship.
\end{abstract}

Keywords: Diverse Books, Database Searching, Critical Race Digital Studies, Radical Cataloging, School Libraries

In most places in the U.S., school librarians are certified teachers who have training in areas such as program administration, collection development, information literacy instruction, collaborative teaching and cataloging. With respect to cataloging, school librarians rarely do original cataloging-relying instead upon publisher-designated subjects and classification schemes like the Dewey Decimal System to add new items to a collection. However, these classification schemes introduce a hierarchy of knowledge that warrants scrutiny by librarians working toward social justice education (c.f. Sweeney, Cooke, VillaNicholas, Roberto, \& Noble, 2014; Gohr, 2017). This study draws on critical race theory (CRT) to examine the relationships between the classification schemes, record formats and other structural agreements that underpin users' ability to find books that are written by and about people of color and/or that foreground contemporary social issues around race, equity, and inclusion (REI).

*Corresponding author, Kafi D. Kumasi, Wayne State University, 106 Kresge Detroit, MI, 48202 Contact: ak4901@wayne.edu Cynthia Jimes, Amee Evans Godwin, Lisa A. Petrides, Anastasia Karaglani, Institute for the Study of Knowledge Management in Education

ว Open Access. ๑ 2020 Kafi D. Kumasi et al., published by De Gruyter. 자 This work is licensed under the Creative Commons Attribution 4.0 Public License. 


\section{Problem Statement}

Numerous studies have examined the lack of diversity in children's books and its relationship to the reading habits and interests of students of color (see, e.g., Heflin \& Barksdale-Ladd, 2001; Bell \& Clark, 1998; Gangi, 2008; Bishop, 2012). In order for school librarians to find, recommend and teach about books that reflect REI themes, they need more sophisticated and user-centered search features that reflect critical race and multicultural analytic frameworks. However, the industry standard structure for cataloging and classifying books is based on a metadata schema, the Machine-Readable Cataloguing (MARC) record, which has limited elements and coding fields where culturally specific information can be recorded and later searched for by users. School librarians, teachers, students, parents, multicultural book enthusiasts and curators can benefit from a new and expanded metadata schema that enables them to search, find and socially tag books in more race and culturally specific ways.

While a growing body of scholarship is focused on the role that classification systems-such as the Dewey Decimal Classification-play in obfuscating and excluding diverse texts (e.g., Olson, 1998; Adler, 2017), few studies explicitly examine how these classification schemes and ideological factors play out in book discovery platforms. Therefore, this preliminary research is a unique contribution to empirical research on this topic.

\subsection{Study Focus}

This study sought to examine what happens when school librarians attempt to identify books that address issues of race, equity and inclusion in the book discovery prototype, the Universal School Library (USL). In particular, we explore the challenges users encounter; the workarounds, tools and vocabularies they use as part of their search process; and the level of cultural competence they bring to the task of searching the USL collection for books with REI themes.

The USL collection contains 2,300 curated books to date, initially identified for inclusion through a process of cross-referencing titles from five contributing public school libraries with recommended book lists such as the Cooperative Children's Book Center (CCBC) and the Young Adult Library Services Association (YALSA). The pilot collection was also evaluated for inclusion in USL by a school librarian review committee comprised of three individuals from rural and urban school districts in Florida, North Carolina, and Washington state-each with experience in building collections that incorporate diverse and underrepresented voices. The review process used was based on criteria including whether the titles were by or about people of color, and whether they aligned to key themes in K-12 education as identified by the review committee, including cultural literacy, career literacy, and college literacy and academic readiness.

As a collaboration between the Institute for the Study of Knowledge Management in Education (ISKME) and the Internet Archive, the USL relies on traditional MARC records, or Machine Readable Cataloguing records- alongside the Internet Archive's online infrastructure for digitized books-including title, description, publication date, topics, publisher, language, and user reviews. The USL also groups books into topics and subjects, such as Race Relations, African American Pioneers, Young Adult, and Civil Rights-which function as filters for narrowing a user's search results. These topics and subjects are derived from the Library of Congress Subject Headings (LCSH), and generally come from OCLC (Online Computer Library Center) or other bibliographic utilities-which in turn aggregate them from publishers and other original sources of cataloguing. The hierarchy that exists in LCSH, such as in "Geography -South America, "is indexed to allow searching for the entire string, or for the individual subjects, so that a user can find results by searching for only "South America," in this example.

A key element of the study was to interrogate the predominantly traditional search and discovery structure for gaps in addressing race, power, and privilege, as a means of giving greater purpose to the curatorial processes of the USL collection in the future. 


\section{Research Questions}

The following research questions have guided the study's preliminary design and analysis:

1. What does the process of discovery and selection of books that support curriculum units on race, power and privilege look like when using a pilot book discovery tool that is undergirded by the traditional MARC record schema?

2. What insights does Critical Race Theory afford in the analysis of the USL prototype and its test users?

3. What changes need to occur to the product to better enable school librarians to integrate race, equity and inclusion into their curatorial efforts?

In answering these questions, the study has sought to contribute design ideas for retooling information discovery platforms in ways that bridge the cultural disconnect that many young adults from historically disenfranchised racial backgrounds have been found to experience in libraries across a range of areas including their perceptions of the library as place (Kumasi, 2019) and having access to culturally relevant books and programming.

\section{Background/Literature Review}

\subsection{Diversity in Children's and Young Adult Books}

One of the perennial debates in the children's and young adult book industry is its lack of diversity-or more specifically, its overwhelming whiteness. In spite of empirical data demonstrating that children's reading achievement and motivation are affected by the availability of literature that is relatable (Heflin and Barksdale-Ladd, 2001; Bell and Clark, 1998; Gangi, 2008), youth from historically disenfranchised racial and cultural groups have had limited access to books that are representative of their backgrounds, experiences, or lives (see, for example, Hughes-Hassell, Barkley, and Koehler's 2009 content analysis of 556 children's books). The Cooperative Children's Books Center (CCBC) provides longitudinal data to support this body of research. Based on examination of books for children and teens since 1994, the CCBC found that until 2014, the percentage of books by and about people of color hovered at around 10 percent of books published each year in the U.S. And although this number increased to roughly 20\% in 2018 (CCBC, 2019), the number of children's books by and about people of color remain disproportionately low compared to the demographic makeup of today's U.S. population.

Similarly, a report on the state of diversity in the publishing industry was created by Jason Low of Lee and Low Publishers and Dr. Sarah Park Dahlen, a professor at St. Catherine University. The report presents the results of a survey to understand the staff demographics of eight review journals and 34 publishers of varying size, from small presses to big publishing houses like Penguin, Random House and Scholastic (Low, 2016). The survey results revealed that the editorial department staff who make decisions about what to publish are overwhelmingly white, heterosexual, non-disabled women.

Optimistically, within the last few years, the major review and research journals commonly consulted in the profession have dedicated issues to the discussion of diversity and the exploration of multicultural literature and its attendant/related characteristics. For example, Children and Libraries, the journal of the ALSC, dedicated the Fall 2015 issue to diversity, with the label "Special Diversity Issue." It covered the range of significant, though predictable areas: reflections on being white, insight from diverse authors and "intentional diversity" in the form of programming,. Similarly, in 2014, the School Library Journal published an issue focused solely on diversity. More recently, School Library Journal published a Diversity \& Cultural Literacy Toolkit (2018) to support school librarian knowledge building around cultural literacy and diversity. It appears that without any system of accountability put in place by librarians and ethnic associations to reverse this pervasive trend of whiteness in children's books (Larrick, 1965), the discussion of diversity 
in publishing would be far more one-sided than it is now, which makes this research critically important.

\subsection{Diversity and Book Discovery Platforms}

As thecall for more diverse books for young peoplehas increased viacampaignssuch as\#weneeddiversebooks, so has the emergence of various book discovery systems that seek to foreground race, equity and inclusion (REI) in resource collections and their underlying metadata schemas. Diversebookfinder.org, for example, provides a searchable database of children's books that include Black and Indigenous People and People of Color (BIPOC), and categorizes those books based on how BIPOC individuals are portrayed.

Within the leading online children's and young adult book databases, there are search features that intersect with diversity, including filters that allow users to search specifically for books that have won awards, or for international books. However, the underlying collection development strategies being employed often remain nebulous for the end user. It is not always clear to librarians what level of knowledge or expertise database designers have, if any, in areas such as multicultural literature, curriculum standards, and childhood development-not to mention race, equity and inclusion. Librarians are therefore left to make sense of not only the myriad of ways that databases organize their content, but also ambiguous website language about how databases curate and classify content.

When race, equity and inclusion are expressed as values within a book discovery platform's design, the focus is usually expressed as an outcome rather than an input. An example of an outcomes -based approach is the Universal School Library (USL), which is the object of study for the article at hand. As discussed above, the USL is a prototype collection of digitized books that seeks to address REI in offering access to the nation's public schools who no longer have librarians or libraries. Providing online book access to students without school libraries can be considered an outcomes-based approach to REI. As this study reveals, a separate and equally important REI related goal of USL is to explicitly discuss the inputs that will go into making the USL an enhanced search infrastructure that enables greater user efficiency in identifying books with racially and culturally explicit access points and metadata schema.

\section{Theoretical Framework}

This study draws from two interrelated areas to inform sensemaking of the intersections of race, technology and user experiences: Critical Race Theory (CRT) and its more recent branch-Critical Race \& Digital Studies $(\mathrm{CR}+\mathrm{DS})$. The following sections expound on each of these areas and their relationship to the current study in greater detail.

\subsection{Critical Race Theory}

Emerging out of critical legal studies in the 1970s, Critical Race Theory (CRT) seeks to unmask and critically examine the endemic racism that has shaped U.S. society as a result of its history of chattel slavery (Bell, 1995; Delgado \& Stefancic, 2001). CRT repositions racism as an entrenched system of inequity that moves beyond individual beliefs, and that permeates all aspects of society (Crenshaw, 1998; Delgado, 1990; Matsuda, 1989).

The literature enumerates five core tenets of CRT. Tenet One of CRT is counter-storytelling. The use of this tenet centralizes the voices and experiential knowledge of people of color as a legitimate and uniquely situated to describe systems and social structures from their vantage point of experiencing the effects of institutional racism on a daily basis.

Tenet two of CRT is the permanence of racism. This tenet begins with the premise that racism is embedded in the social fabric of American society and from a CRT perspective is regarded as an inherent part of civilization, privileging white people over people of color. 
Tenet Three is whiteness as property. This tenet maintains that the period of slavery and conquest of African and native peoples helped solidify "a type of status in which white racial identity provided the basis for allocating societal benefits both private and public in character. These arrangements were ratified and legitimated in law as a type of status property. Whiteness as property operates on different levels, such as the right of possession, the right to use and enjoyment, the right to disposition, and the right of exclusion (Harris, 1993; Ladson-Billings, 1998).

Tenet four of CRT is interest convergence. This tenet was posited by Derrick Bell and maintains that whites will advocate for/tolerate racial advancement among people of color only when it is in their interest to do so. This tenet also acknowledges white people as being the primary beneficiaries of civil rights legislation, which is exemplified in affirmative action and diversity initiatives, such as, for example, legacy status in college admissions.

Finally, tenet five is the critique of liberalism. This tenet challenges the notion of colorblindness, the neutrality of the law and the slow pace of racial reforms rooted in the benign language of multiculturalism and equality. According to this tenet, colorblindness is a mechanism allowing people to ignore racist policies and epistemologies that perpetuate social inequity.

\subsection{Critical Race \& Digital Studies}

A critical race \& digital studies approach makes visible the biases and weaknesses in technology applications and iteratively designs new solutions. In that sense, a CR+DS lens can help to bridge the gap between what we imagine technology to do and what it really does. It is argued that technology studies too often obfuscate the way technology and race intersect. For example, smart city narratives work from a premise that cities will be smarter and more efficient with access to big data. However, these presumably objective observations of data often reproduce existing inequalities within cities (Korn, 2018).

Ruha Benjamin (2019), a leading voice in critical race and digital studies, contends that CR + DS gives scholars and technology workers alike a set of tools to disrupt the fallacy that science and technology are 'inevitable' or unchangeable by users and designers. Benjamin highlights a potential lack of sociocultural literacy on behalf of technology developers, which often results in products that reinforce and exacerbate existing power asymmetries and discriminatory practices. Similarly, Noble (2018) discusses research findings demonstrating how racial bias was "baked in" to the algorithms of the Google search engine, wherein the keyword "Black women' "produced pornographic and stereotypical images contrasted with more studious and clean images that were produced when searching with the keyword "white women." Scholars such as Benjamin and Noble use CR +DS to look at our biases and what we put into technology, and argue for making adjustments to that go against conventions and help mediate against the effects of racism and discrimination in the design phase ( see e.g. Broussard, 2018; Mills \& Godley, 2017). In this sense CR-DS is hopeful, not deterministic-as it examines the ways that people of color subvert existing technology systems (e.g. social media) and use them for liberatory purposes (Samuel 2015).

$\mathrm{CR}+\mathrm{DS}$ originated within the Center for Critical Race and Digital Studies, which describes itself as a network of scholars of color focused on examining the relationship between how technologies are designed and the impact of those technologies on race, ethnicity, identity and power structures within communities of color (Center for Critical Race and Digital Studies, n.d.). The agentive aspects of CR+ DS align well with the contextual design methodology employed in this study, which is described in the next section. In short, both assume a pragmatic theoretical stance that is focused on improving systems through a people-oriented approach.

\subsection{Critical Librarianship, Cataloging and Classification}

Within the field of library and information science, there is a movement for metadata justice, radical cataloging and scholarship addressing the critique of whiteness in library management systems, which aim 
to incorporate social and racial justice into the ways that books are categorized in information discovery systems and schemas (cf. Berman, 1983; Jenson, Stoner \& Castillo-Speed, 2019; Schlesselman-Tarango, 2017; Roberto, 2015). Rooted in the argument that classification schemes are the subjective products of our social and historical context, and thus espouse the endemic racism, classism and sexism of the individuals who created them (Drabinski, 2008), librarians and scholars alike are seeking solutions that are more dynamic and that incorporate the voices of users into their classification schemes (see, e.g., Olson, 2001).

Through a call for new subject headings, keywords and tags that foreground race, equity and inclusion (Angela et al., 2018), this body of work also seeks to make multicultural books more discoverable by librarians in support of their role as reading promoters and technology leaders in their schools, particularly in an increasingly digital environment (c.f. Wolf, Jones \& Gilbert, 2014). And yet, there appears to be a knowledge gap among school librarians with regard to the intersections of REI and the technical infrastructure of the book discovery platforms that they use to locate books by and about people of color. This gap stems in part from the curriculum standards of school library preparation programs, which do not uniformly cover knowledge of cataloging and classification schemes (Davis, 2008). Another curriculum area within school librarian preparation that one of the authors personally finds wanting is related to the study of technology and information. Future school librarians could benefit from a critical informatics approach to the study of technology and information (see e.g. Sweeney \& Brock, 2014) as it foregrounds the role of race and culture in these systems and tools.

Successfully curating books that foreground race, equity and inclusion, entails understanding the various cataloging, classification and metadata schemes that undergird the platforms and collections in which they are housed. In some cases, however, school librarians may be unaware of the fact that many platforms are built upon knowledge organization systems (KOS) that may work to reinforce existing racial hierarchies.

\section{Methods}

The researchers employed a contextual design methodology to help uncover what happens when two school librarians search for books that support curriculum units on race, power and privilege in a pilot book discovery platform known as the USL. Contextual design is rooted in the notion that technology is always part of a larger practice and context on behalf of users and asks how technologies can be improved based on the user experience. The approach illuminates users' intents and needs through field testing and talking with users at the point of their interaction with the technology under study (Holtzblatt, K., Wendell, J.\& Wood, S., 2005). The data gathered in the contextual design process is then used to create and prototype product and service concepts, and to iteratively refine those concepts with users.

As outlined further below, the study leveraged a two-pronged approach to contextual design to interrogate both the USL product and the broader sociocultural background and competencies of its users.

\subsection{Social Location of Researchers and Participants}

The research team for this study was comprised of one associate professor of library and information science and four researchers from an education nonprofit that conducts independent studies on the use and application of digital resources and technologies in teaching and learning. Four members of the research team identify as White/Caucasian, and female, and the fifth member as Black/African American and female. One member of the research team identifies as a non-native English speaker. Each member of the research team is connected to the information sciences and has an interest in using their scholarship and user design backgrounds to make library spaces and technologies more equitable. The research team was also involved in the development of the Universal School Library's book collection, in partnership with the Internet Archive.

For the self -identified Black female researcher, having a critical race orientation towards research 
means acknowledging that being the only woman of color on the research team who also is confronting whiteness in a field that is predominantly white is a unique burden that can complicate the research process. Having this critical race theoretical background and being from a historically underrepresented racial group undoubtedly informed multiple aspects of the study including the choice to employ CRT as an analytic frame and to infuse race, power and privilege into the collaborative lesson plan assigned to the two school library participants.

The research participants include one elementary library coordinator with 13 years of combined experience as a librarian and classroom teacher, and who identifies as White/Caucasian. The other research participant is a current middle school media specialist and former long-time high school English teacher who identifies as a white, cis-gendered female. At the time of the study, both of the in-service librarians were candidates for the Experimental School Library Media Certificate Program in the Graduate School of Information Sciences at Wayne State University. Both school librarians responded to an invitation to participate in the study while enrolled in a graduate course titled "The School Librarian as Teacher and Instructional Consultant," taught by one of the study's authors. The course was focused on school librarians' development of collaborative lessons that address race, power and privilege in collaboration with teachers in their schools. As per the requirements of the course, the study's participants utilized the Universal School Library (USL) database, an open access resource, for identifying anchor texts for inclusion in their lessons.

\subsection{Data Collection}

In the summer of 2019, the study's researchers conducted web-based interviews with the two participating school librarians. Following Holtzblatt and Beyer's (2016) rapid contextual design, the interviews sought to uncover the workflows and tasks undertaken by both participants during use of the Universal School Library, a collection of digitally scanned books available for lending from the Internet Archive, in order to construct enhanced technology design that incorporates users' life contexts, needs, and even identities.

During one-hour inquiry sessions using screen share from the participants' computers, both were asked to provide a retrospective account of the search and discovery tasks undertaken when searching for anchor texts to include in their lessons addressing race, power and privilege. To initiate the inquiry session, the following prompts were used:

Using the USL database, walk me through your process of searching for and selecting an anchor text to include in your instructional unit that addresses race, power and privilege. As you think aloud, demonstrate how you searched for, evaluated, and selected the anchor text for inclusion in your lesson. If you did not end up using the USL database to select your anchor text, show me where USL fit in to your selection, if at all.

When steps of the search and discovery process were skipped by participants-or summarized without detail-they were prompted by the researchers to recount activities with additional description. Participants were also prompted to describe supporting tools or artifacts used alongside the USL database as part of their search and discovery effort.

After the interview sessions, participants were asked to respond in writing to four prompts focused on understanding the supports needed to enable their curation practice. Examples of prompts include: To what extent do you feel prepared to integrate race, equity and inclusion into your curatorial efforts as a school librarian?, and How might school librarians be better prepared to integrate race, equity and inclusion into their curatorial efforts (i.e., what supports do they need)? 


\subsection{Analytical Framework}

Our analytic frame combines elements from rapid contextual design and critical race theory. Thus informed by Holtzblatt and Beyer's (2016) conceptualization of rapid contextual design, the analysis sought to move beyond the "cognitive load" or "steps of a task" that have traditionally defined user-centered design, toward design that incorporates users' life contexts, and provides transformative products that "create moments of surprise and sensory delight" (p.). Likewise, one of the goals of this study is to transform the way information discovery platforms are designed such that users are surprised, delighted and informed by the way their identities and larger societal constructs such as race, power and privilege are accounted for in the product itself.

Throughout the analytical process, we used three tenets of critical race theory to highlight the gaps between what the school librarian participants are asking the USL technology to do and the barriers that prevent them from doing so:

1. The tenet of whiteness as property asks how structural agreements such as metadata schema and controlled vocabularies reinforce exclusionary practices that benefit white people and Eurocentric ways of knowing.

2. The tenet of experiential knowledge prompts us to ask whose voices, perspectives, experiences, language are sanctioned as authoritative and whose get marginalized or silenced in formal spaces and institutions such as libraries. There is also a recognition that, by experiencing racial domination, people of color perceive the system differently and are often uniquely placed to understand its workings.

3. The tenet of critique of liberalism asks how racial reforms are stagnated and stalled in an attempt to protect the status quo of entrenched power.

Throughout the coding of the interview transcripts, we mapped the themes from the data onto one of the above tenets of CRT, iteratively moving back and forth between the two phases of rapid contextual design: immersion in data and product ideation. Our findings reflect an iterative dialogue between theory, literature, data analysis and user centered design.

\section{Findings/Discussion}

In placing the user experiences of the two school librarian participants in conversation with the scholarship on Critical Race Theory, several design issues, challenges and possibilities emerged. For each CRT tenet chosen, the findings discussion begins with data collected from the 'current state' of the USL prototype that the users experienced. The discussion then moves to the 'future state' of the USL prototype, which features design ideas and strategies for improving the book discovery platform based on the emergent themes in the user experience data juxtaposed against the scholarly literature for the respective CRT tenet.

\subsection{Whiteness as Property}

\section{Current User State: Search Strategies}

Both school librarians described their search in the Universal School Library collection as limited and unhelpful. The first school librarian explained her search approach as follows:

I did use the search [bar] within the USL. I tried race. I tried power. I tried white privilege [....] I did search for civil rights and civil rights movement. [...] If [I used] a search term like privilege or white privilege or cultural perspective [...] it didn’t seem to yield results that were helpful. It's a hard search [to find books that address race and privilege]. You might end up pulling information that you don't need at all. It seems to be a tough search in general.

The second school librarian echoed these results when demonstrating her search process during the interview. 
Well, the first time that I went into USL [...] I felt like I was kind of hunting around a bit and how to access it. [...] I typed in race, for example, to the USL prototype, and the first thing that jumped out at me is that with the exception of "Scorch Trials," which is a different kind of race, there is really only the young adult book that is listed there.

One of the key features of whiteness that gives it its property-like status is the right to exclude. The fact that these race and power differentiated vocabularies were unavailable in the database search results speaks to way whiteness acts as a default cultural norm that maintains invisibility while at the same time holds the power to exclude terms that might confront white supremacy and/or name various forms of oppression. Because terms like "race" and "white privilege" are not part of the lexicon that the majority white population (including school librarians) often feel comfortable using, the result is that the classification schemes and controlled vocabularies that underpin mainstream book databases reflect this same preference for neutral vocabularies. These vocabularies then get replicated over and over across generations in what Delgado, Wing, \& Stefancic (2015) describe as the 'racial double helix' which mimics the biological permanence that occurs in genetic coding (aka DNA). To further illustrate this point, one of the school librarian participants spoke about the search terms her students would be likely to use (or not use) in the book discovery platform. She stated:

Especially in terms of the ways that I imagine middle school students using this, my kids are not going to necessarily look up race or racism, but they might look up police brutality or police shootings or things like that. Right, so it's hard to predict what language they might use to actually do a search, but the likelihood that a kid who's looking for a book, that level of specificity is going to be hard to reach in terms of the tags of the MARC data.

There appears to be an understanding that terms like race and racism are not within the normative speech practices that middle school students would use in a book search process, particularly in an academic setting. This begs the question of why vocabulary around race and racism would not likely be used by middle school students and what impact that might have on students' ability to make sense of their world. CRT scholars might call this type of silencing or omission of language and vocabularies that speak to the racial experiences and pain of people of color a form of 'narrative violence' (Delgado, WIng \& Stefanic, 2015). This sort of silencing stems from the legacy of slavery in America and the attendant sense of white guilt that some whites feel about their connection to the enslavement of Blacks (both perceived and literal slave owning family history) that causes tensions in racial dialogue still today. Similarly, Honma (2005) argues that new terminology such as diversity and inclusion that regularly emerge in LIS discourses favor neutral perspectives on difference and wind up having little structural impact in their attempts to treat all facets of difference equally.

Later during the follow up interviews, the participants were asked about [their perceptions of] school librarians' role in social justice education. Both participants spoke about the importance of training and professional development opportunities that would assist school librarians in integrating race, equity and inclusion into their curatorial efforts. One participant stated:

White women librarians need antiracist training that supports them in the journey toward understanding their own privilege and developing skills at inclusive text curation.

More broadly speaking, both participants cited several intersections between the work of school librarians and social justice efforts in education including such areas as: 1) purchasing and promoting books and resources from diverse perspectives; 2) modeling of antiracist curricula; 3) offering input on curriculum materials to guard against the "single story" (Adiche,2009); 4) Constantly questioning the impact of pedagogical choices; and, 5) bringing a broader perspective to their role in professional development on social justice such as leading school based teams, workshops and invited lecture or author series.

\section{Future User State: Search Strategies}

The tenet of whiteness as property helps reveal the limits of controlled vocabulary and MARC records to encode the kind of power differentiated vocabulary that the school librarians needed to have at their 
disposal as they searched the USL prototype for books with an explicit race, equity and inclusion lens. One school librarian participant proposed ideas for expanding the controlled vocabularies or metatags of the USL prototype in ways that reflect race consciousness, musing that:

If a search term like privilege or white privilege, or cultural perspective [...] it didn't seem to yield results that were helpful. If that information could pull more books [...] that would have been helpful.

One of the ways the USL prototype could mediate against this kind of benign neutrality in its design process would be to create new subfields in the MARC record where culturally specific information about the author or creator of the work can be assigned (e.g. African American author) and create a sub-coding of author for the 100 field or utilizing the 386 to record group categories of creators and contributors of works, expressions, and persons.(See Figure 1).

Figure 1

\begin{tabular}{|c|c|c|c|}
\hline $\begin{array}{l}\text { MARC } 21 \\
\text { Tag or Field Code }\end{array}$ & Field Definition and Scope & $\begin{array}{l}\text { Proposed New } \\
\text { or Enhanced } \\
\text { Subfield Code }\end{array}$ & $\begin{array}{l}\text { Proposed New } \\
\text { Field/Subfield Definition and Scope }\end{array}$ \\
\hline $386(R)$ & $\begin{array}{l}\text { A group category to which the creator(s) } \\
\text { of a work or compilation of works, or } \\
\text { the contributor(s) to an expression or } \\
\text { compilation of expressions, belongs. }(\$ \mathrm{~m}) \\
\text { Demographic group term (NR) } \\
\text { Example: } \\
\text { Serbian poetry } \$ m \text { Muslim authors }\end{array}$ & $\$ m$ & $\begin{array}{l}\text { Author Self Identification used for the author’s } \\
\text { self-identified descriptors generally. } \\
\text { First and Second Indicators are Undefined (\#) } \\
\text { Example: } \\
386 \\
\text { \#\#\$mGender group\$aWomen\$2lcsh }\end{array}$ \\
\hline $520(R)$ & $\begin{array}{l}\text { Summary, etc., used for a summary, } \\
\text { abstract, annotation, review, or only a } \\
\text { phrase describing the material. } \\
\text { First Indicator: } 1 \text { - Review and Second } \\
\text { Indicator - Undefined (\#) } \\
\text { Example: } \\
5201 \# \$ \text { a"Appropriate for high school } \\
\text { classrooms"-- Teacher rating guide, winter } \\
2010 .\end{array}$ & $1 \# \$ a$ & $\begin{array}{l}\text { Multicultural reviews and annotations that } \\
\text { include user created reviews, tags and } \\
\text { annotations } \\
\text { First Indicator: } 1 \text { - Review and Second Indicator } \\
\text { - Undefined (\#) } \\
\text { Example: } \\
5201 \# \$ \text { a"Appropriate for teaching about } \\
\text { race and multicultural identity"--Detroit high } \\
\text { school teacher, } 2020 .\end{array}$ \\
\hline $520(R)$ & $\begin{array}{l}\text { Summary, etc. } \\
\text { First Indicator: } 2 \text { - Scope and content, used } \\
\text { to generate the display constant Scope } \\
\text { and content: } \\
\text { Example: } \\
5202 \# \$ \text { aSeries consists of minutes of } \\
\text { board meetings and documents referred to } \\
\text { in the minutes... }\end{array}$ & d $2 \# \$$ & $\begin{array}{l}\text { Multicultural curriculum integration } \\
\text { Example: } \\
520 \text { 2\#\$amcSeries of multicultural lessons } \\
\text { for English Language Arts, grade 9, aligned to } \\
\text { State Standards for Michigan }\end{array}$ \\
\hline 09X, & $\begin{array}{l}\text { Reserved for local call number use and } \\
\text { local definition. For interchange purposes, } \\
\text { documentation of the structure of the } \\
\text { 09X fields and input conventions must } \\
\text { be provided to exchange partners by the } \\
\text { organization initiating the interchange. } \\
\text { These may be locally developed } \\
\text { classification systems or systems NOT } \\
\text { widely used as those specified by USMARC }\end{array}$ & \#ownvoices & $\begin{array}{l}\text { Local data to curate hashtags that capture } \\
\text { trending topics on social media centered } \\
\text { around the publication of books in the } \\
\text { collection that are mentioned in relation to } \\
\text { issues of diversity, representation, cultural } \\
\text { authenticity } \\
\text { Example: } \\
\text { \#Ownvoices, author positionality as a person } \\
\text { of color writing from firsthand lived experience }\end{array}$ \\
\hline
\end{tabular}

Legend: Terms used in Figure 1

Tag or Field Code The 3-digit numbers that precede the names of the fields they represent, like a directory

Indicators The one-digit numbers in two independent positions that supplement and further define the data in a subsequent field

Subfield code Letter code used to distinguish the different data elements, with each subfield code preceded by the character \$, signifying a delimiter, that is, a character used for separating data elements.

See https://www.loc.gov/marc/umb/um07to10.html for additional detailed information. 
Clarke and Schoomaker (2018) offer a similar, albeit slightly more provocative, design solution to this dilemma with their idea of using library cataloging systems such as Resource Description and Access (RDA), to flip the script on white male heteronormativity in the search process by only labeling books written by white cis able-bodied men. This way, when users search for books, the only things returned are books that are not by white cis able-bodied men. The authors contend that "Including demographic descriptors for this male category resists white normativity that frames this male category as "a neutral or standard category of human beings...potentially relinquishes marginalized groups from strident or incorrect categorization while de-stabilizing the patriarchal norm.(p.25)"

The USL could build on this and other radical cataloging approaches by enhancing or repurposing the traditional MARC content designators--tags, subfield codes, and indicators. For example. the USL prototype could also market a new use for the 9XX tag, which is traditionally left for locally-defined uses such as local barcode numbers. For example, the specific fields 901-907, 910, and 945-949 have been defined for local use and will pass OCLC validation, while other 9XX fields may be locally defined but may not pass OCLC validation. Instead of depending solely on the local library to define the type of information that will be attached to the 9XX tag, the USL might provide a template that can be used locally by school librarians (and/or students) to categorize critical race and multicultural elements of the book using frameworks such as Rudine Sims Bishop's (1990) “mirrors, windows, sliding glass doors”.

In explaining the 9XX field, Crawford (1984) notes that there are other fields that might make use of this local "X9Xs in each of these groups -- 09X, 59X, etc. are also reserved for local use, except 490". This means that there are other MARC fields beyond the 900 local use field that could be used to denote critical race and multicultural frameworks such as 4XX- Series Statements; 5XX-Notes; 6XX Subject Added Entries; and others. Since 9XX fields are often used by libraries for tasks that can't be seen by users, we propose using X9X, specifically 09X, for the purposes of supporting local classification by enabling additional descriptions by local school librarians as well as their students].Again, Figure 1 proposes some new uses for existing MARC fields and some new subfields aligned with the user feedback and with ideation among the design teams.

\subsection{Critique of Liberalism}

Current User State: Subject Headings \& Collections

In describing their experiences with the USL subject headings and collections features, the two school librarian participants were uncertain about how they were organized, who created or contributed to them, and how the resources found might fit into their existing thematic unit plans. The CRT critique of liberalism tenet, which favors a more aggressive race-conscious approach to social transformation than liberalism's more cautious, colorblind approach, can help explain barriers the users' experienced while searching for topics and subject headings that would yield possible anchor texts for lessons related to race, power and privilege. One school librarian participant sought clarification on the organization, of the collections asking: "I'm just curious about whether there were collections that were already built around my themewhich I did not find. And I may have missed a collection already designed." The other participant commented on the contributors, noting that: [...] the collections were interesting because they were collections that can be created by others.

As the organizational structure of the subject headings and collections became clearer, the participants began commenting on the aboutness of the subject headings and collections themselves.

“[Then] I did look through topics and subjects. [...] There's a topic here. I think it's race relations or some heading like that, that I looked through and then read a little bit more about each book to see if it would have any Issues that would be relevant for extensions for our issue which looks at portrayals in arts and media. [...]-- ? 
Similarly, the other participant observed:

I didn't pull up by topic and subject, but I did look at I did look through some of the civil rights... There's a couple... There's civil rights... civil rights movement. So I think I just did a search there. I did look at African Americans juvenile fiction.

The participants' struggles with finding anchor text around race, power and privilege in the database are directly related to the way certain events and periods in U.S. such as slavery are presented in sanitized or whitewashed ways. This phenomenon has led to heated online discussions about the appropriateness of American children's books on ethnic and racial issues (Klęczaj-Siara, 2018). This same sort of colorblind and benignly neutral reference to historical events related to race and racism exists library subject headings and classification schemes related to race and racism (Adler, 2017). For example, creating a subject heading called "Civil Rights Movement" rather than "Black Power Movement" masks the particularities of who was being oppressed (Black Americans) and what they were fighting to overcome (racism and white supremacy). This sort of linguistic shift would also align with a key CRT tenet, which recognizes the centrality and permanence of race and racism in America that is rooted in 400 years of slavery among people of African descent.

The critique of liberalism tenet has relevance to not only legal matters but also to the field of library and information science, particularly as it relates to cataloging and classification. For example, whenever Black Americans attempted to hold the American judicial system accountable to its constitutional creed of "liberty and justice for all" they were met with prolonged and retracted struggles in the courtroom. Librarians experienced these same sort of stall tactics to uphold the status quo when attempting to correct and replace outdated, offensive subject headings and add new culturally conscious vocabulary to the Library of Congress Subject Headings (LCSH). CRT can help make sense of these power struggles and provide strategies to mitigate against them.

\section{Future User State: Subject Headings \& Collections}

Radical cataloging methods could be integrated into the Universal School Library prototype to help disrupt the dominant white ideology upon which the underlying structures of many cataloging and classification schemas are built. This would entail shifting the focus away from providing access to diverse books for students without school libraries, towards developing a discovery platform that reflects the ways young people engage with texts and media based on their sense of self and racial identity.

Users from historically disenfranchised backgrounds have invoked social tagging and folksonomies to exert agency, with the Black Twitter community, and the \#BlackLivesMatter hashtag, for example, capturing an unspoken sense of group identity, or fictive kinship, among people who share racialized experiences (Brock, 2012). Although democratic in nature, the inherent lack of organizational structure and precision within folksonomy-based systems has been found to hinder search and retrieval within resource collections, as tags are often conflated when similar, too general to be meaningful, or irrelevant beyond the individual user's own collection (see Bullard, 2017). In a similar vein, the school librarian participants for the study at hand reported that their uncertainty about the criteria used to create user-generated collections in the USL prototype served as a barrier to their review and use of those collections.

In alleviating the challenges with folksonomies, while at the same time prioritizing local community knowledge, the next stage development of the USL and other technology enabled search tools could benefit from exploration into "curated folksonomy" approaches, where end-users design and drive a collection'scontrolled tagging structure. Julia Bullard's work on curated folksonomies explores three such initiativesincluding the Archive of Our Own (AO3), Library Thing and Stack Overflow -all of which leverage user voting and other community protocols to map user-created tags to site-wide, controlled vocabularies (Bullard, 2017; Bullard, 2018). In exploring these models for the development of the USL, multiple stakeholder groups, including librarians, teachers, parents, and students themselves could be considered as participants in a potential curated folksonomy system to advance the USL classification and its vocabularies. 


\subsection{Experiential Knowledge}

\section{Current User State: Reviews, Recommendations and Trusted Sources}

Currently, the USL collection was curated internally from a range of professional review sources such as book award lists. However, users are not able to directly access these reviews on the user-facing side of the interface. There is also a user-generated book review tag feature in the Internet Archive system, which has not been utilized yet by any users of the USL Collection. When discussing the criteria, they used to select books, both school librarian participants for the study at hand stated the need to go outside the USL platform to consult trusted or authoritative book review sources. As one participant reported:

I use Titlewave as a source to look for reviews. They do a nice job of aggregating, especially for school libraries, and I was looking for 11-12 grade wise, and we wanted to have a mix of reading levels, and I was curious to see what Title Wave [...] I was looking for some other reviews for grade levels, and not just overall review of book like USL had and wanted to see how applicable it was for our setting.

Follet's Titlewave is an online collection development tool that includes reviews-sourced from the School Library Journal-of its 12,000 pre-K-12 titles. Titlewave's search tools allow users to sort through popular titles and starred reviews by grade level, subject and genre, award winners, and curriculum tags. Librarians are among a privileged minority of "experts" who review books for publications such as the School Library Journal. As such, librarians decide which books are deemed worthy of recognition in the form of honors and awards.

Because educators and other curators rely on these reviews to build their collections, the librarian's role as a gatekeeper in the publishing industry is undeniable. From a CRT perspective, examining who gets to decide whether a book is worthy of recognition and whether it is culturally authentic are central questions that librarians and the field at large would benefit from exploring-especially in light of the overrepresentation of white practitioners in the field of Library and Information Science.

In this vein, one of the school librarian participants in the study further related how concerns about cultural authenticity factor into her book selection process:

In reviewing books, I haven't read, I'd pay attention to what culture or group the story is about, and then I'd do additional research like, does the author have personal experience to speak on this topic.

The other participant similarly stated:

\footnotetext{
The resources that I typically use when I'm looking...like I always start at [the website] We Need Diverse Books, and then that organization has links to all kinds of different lists of a multitude of different backgrounds and cultures, including using Debbie Reese's resources about Native American stories and storytelling. But my starting point is always We Need Diverse Books, that's where I go to get recommendations and then I would say my knowledge of contemporary fiction comes from my PL [informal professional learning network] and from social media and not necessarily from a book collection itself.
}

As in CRT scholarship, the study's school librarians are placing importance on actual lived experiences, and the experiential knowledge of people of color, potentially recognizing that because such groups often perceive the system differently, they are often uniquely placed to understand its workings (see, e.g., Taylor, Gillborn \& Ladson-Billings, 2009). The section below outlines explorative ways to address this tenet in the design of the Universal School Library.

\section{Future User State: Reviews, Recommendations and Trusted Sources}

A key step in honoring CRT's experiential knowledge tenet in the USL redesign would be to provide avenues to recognize the voices, perspectives and stories of those people whose experiences are often not told, including people of color. For guidance, one might look to the radical cataloging work being done by indigenous communities to ensure that there is proper representation in cataloging that incorporates works not only ABOUT indigenous people but BY them as well (Roberto, 2015) Beyond including author 
descriptors to support the curation of books by underrepresented communities (see Figure 1 above), users could be provided with opportunities to add their critical evaluation of books for cultural authenticity. Within a book review function, prompts could be used to help gather input on the cultural authenticity of the books that users read; this feature could also be replicated for student-written reviews as well. For librarians looking to consult trusted book recommender sources that reflect cultural authenticity, the USL platform could enable book review tags that are curated from well-known blogs written by people of color (e.g. We Need Diverse Books) and critical whiteness perspectives (e.g. Reading While White).

\section{Study Limitations}

Although the contextual design methodology provided a useful mechanism for linking the search strategies and requirements of in situ school librarians to redesign enhancements for the USL prototype, there are limitations to be noted. Foremost, the breadth and scope of the user experience is not generalizable as it is limited to only two respondents, who were both self-identified white librarians. Future research would benefit from not only more participants, but greater representation of the unique perspectives that school librarians of color might bring to this culturally-specific topic. Furthermore, the proposed enhancements to the MARC field codes may inadvertently limit visibility if they are not compliant with OCLC (Online Computer Library Center) validation rules for cataloging, which is a highly technical skill that most school librarians may not be familiar with. Finally, the current interface of the USL does not include a mechanism for determining the identities or affiliations of the users who create collections. This limits the kind of search that can be conducted and therefore the ability to aggregate data and discern patterns for user analytics purposes.

\section{Conclusions \& Implications}

It is clear that there are multiple spheres of influence that shape both the content and technical infrastructure for book discovery platforms such as the Universal School Library. The findings suggest that school librarians need better education and training in the intersections of cataloging, classification and critical race scholarship. With such knowledge, they can lead their own bottom up radical cataloging initiatives that bring this very nuanced work to their everyday practices with K-12 students and teachers. Part of this education should focus on the development of critical multicultural frameworks that would ultimately be used to catalog and classify books with the language and perspectives of people of color at the forefront of the analyses. The decision about which frameworks (e.g., \#Ownvoices) should be chosen is a nuanced task that will likely evolve from case study approaches that are disseminated more widely once they have been honed by school library practitioners. The findings also point to the need for a common vocabulary around issues of race, equity and inclusion that can simultaneously cut through the ambiguity of social tagging and yet subvert the status quo of entrenched liberalism and/or latent racist ideologies embedded in traditional classification schemes.

The two librarians in this study reflect a growing recognition that social justice education is an important role for school librarians to assume. Yet, the creators of the technological structures that school librarians use to find books for students need similar critical race lenses when they create these tools and structures. School librarians are already tasked with multiple roles in the school from information specialists, to technology leaders, to instructional partners and reading promoters. Therefore, they need more partners in education (teachers, technologists, administrators, students) who are committed to developing a greater understanding of the intersections between race and technology. Given the dearth of CRT scholarship written by white authors, it stands to reason that the majority white technology workforce in America who design databases such as the ones that underpin the USL, are unfamiliar with the critical vocabularies and concepts that CRT introduces. With greater cultural competency, or the ability to understand, communicate with and effectively interact with people across cultures, technologists could help facilitate more fluid connections between critical race theory and information technology practices. Building one's 
own cultural competence can be seen as part of the anti-racist work at the center of CRT activism. Getting to know someone of a different cultural background and understanding the way they think, act, and talk can be a life-saving gesture, especially for people with white skin privilege who possess power over the lives and livilhood of people of color in different spheres such as policing, housing, employment, etc, Overall, this study helped demonstrate that a book discovery platform, like any product, can be better designed in ways that reflect the racial realities of users' lives and work if the designers themselves are attuned to the ways in which people of color read both the word and their worlds.

\section{References}

Adichie, C. N. (2009). The danger of a single story. Retrieved from https://dobk.pw/983.pdf

Adler, Melissa. (2016). The case for taxonomic reparations. Knowledge Organization, 43(8), 630-640.

Adler, M. (2017). Classification along the color line: Excavating racism in the stacks. Journal of Critical Library and Information Studies, 1(1). Retrieved from https://pdfs. semanticscholar.org/c55b/2317dedef943ad0f1a2986098a9ede1b4577.pdf.

Angela A., Adrián Barragán-Álvarez, J., Echeverria, F, Lang, J., Lee, C., \& Shiraishi, N. (2018). Report: Task group on social justice in academic libraries. Library Association of the University of California, Berkeley.

Bell, D. A. (1995). Who's afraid of critical race theory. University of Illinois Law Review, 1995(4), 893-910.

Bell, Y. R., \& Clark, T.R. (1998). Culturally relevant reading material as related to comprehension and recall in African American children. Journal of Black Psychology, 24(4), 455-75.

Benjamin, R. (2019). Race after technology: Abolitionist tools for the new jim code. Hoboken, New Jersey: John Wiley \& Sons.

Berman, S. (1983) Prejudices and antipathies: A tract on the LC subject heads concerning people. Jefferson, NC: McFarland and Co Publishing.

Bishop, R.S. (2012). Reflections on the development of African American children's literature. Journal of Children's Literature 38(2), 5-13

Brock, A. (2012). From the blackhand side: Twitter as a cultural conversation. Journal of Broadcasting \& Electronic Media, 56(4), 529-549.

Bishop, R. S. (1990). Mirrors, windows, and sliding glass doors. Perspectives, 6(3), ix-xi.

Broussard, M. (2018). Artificial unintelligence: how computers misunderstand the world. Cambridge, MA: MIT Press.

Bullard, J. (2018). Curated folksonomies: Three implementations of structure through human judgment. Knowledge Organization, 45(8), 643-652.

Bullard, J. (2017). Classification design: Understanding the decisions between theory and consequence (Doctoral dissertation). University of Texas, Austin.

Center for Critical Race and Digital Studies. (n.d.). CR+DS. Retrieved from https:// criticalracedigitalstudies.com/.

Clarke, R. I., \& Schoonmaker, S. (2018). The critical catalog: Giving voice to diverse library materials through provocative design. Advances in Classification Research Online, 29(1), 23-26.

Cooperative Children's Book Center [CCBC] (2019). Publishing statistics on children's/young adults books about people of color and first/native nations and by people of color and first/native nations authors and illustrators. University of Wisconsin, Madison. Retrieved from https://ccbc .education.wisc.edu/books/pcstats.asp\#charts.

Crawford, W. (1984). MARC for library use: Understanding the USMARC formats. White Plains, NY: Knowledge Industry Publications

Crenshaw, K. (1998). A black feminist critique of antidiscrimination law. The Politics of Law: A Progressive Critique, third edition. New York: Basic Books.

Davis, J. M. (2008). A survey of cataloging education: are library schools listening?. Cataloging \& Classification Quarterly, 46(2), 182-200.

Delgado, R. (1990). Campus antiracism rules: Constitutional narratives in collision Northwestern University Law Review 85(2), 343-387.

Delgado, R., Wing, A. K., \& Stefancic, J. (2015). The Racial Double Helix: Watson, Crick, and Brown v. Board of Education. In Law Unbound! (pp. 105-112). Routledge.

Drabinski, E. (2008). Teaching the radical catalog. In (K.R. Roberto, Ed.), Radical cataloging: Essays at the front. Jefferson, N.C.: McFarland.

Gangi, J. M. (2008). The unbearable whiteness of literacy instruction: Realizing the implications of the proficient reader research. Multicultural Review, 17(1), 30-35.

Gohr, M. (2017). Ethnic and racial diversity in libraries: How white allies can support arguments for decolonization. Journal of Radical Librarianship, 3, 42-58.

Harris, C. I. (1993). Whiteness as property. Harvard law review, 1707-1791. 
Heflin, B. R., and M. A. Barksdale-Ladd. (2001). African American children's literature that helps students find themselves: Selection guidelines for grades K-3. Reading Teacher, 54(8), 810-19.

Holtzblatt, K., Wendell, J.\& Wood, S. (2005). Rapid contextual design: A how-to guide to key technologies for user-centered design. San Francisco: Morgan Kaufman Publishers.

Holtzblatt, K., \& Beyer, H. (2016). Contextual design: Evolved. Synthesis Lectures on Human-Centered Informatics, 7(4), 1-91.

Honma, T. (2005). Trippin' over the color line: The invisibility of race in library and information studies. InterActions: UCLA Journal of Education and Information Studies, 1(2). Retrieved from https://escholarship.org/uc/item/4nj0w1m.

Hughes-Hassell, S., Barkley, H.A., \& Koehler, E. (2009). Promoting equity in children's literacy instruction: Using a critical race theory framework to examine transitional books. School Library Media Research, 12, 1-20. Retrieved from http://www.ala. org/aasl/slmr/volume12/hughes-hassell-barkley-koehler.

Jenson, Stoner\& Castillo-Speed (2019). Archives for Black Lives in Philidelphia: Anti-racist description resources. Retrieved from https://archivesforblacklives.files.wordpress.com/2019/10/ardr_final.pdf

Klęczaj-Siara, E. (2018). Slavery with a smile-the media controversy about children's literature on the topic of slavery and the rhetoric of the publishing industry. Res Rhetorica, 5(2), 54-63.

Kumasi, K. (2019). The library is like her house: Reimagining youth of color in LIS discourses. In Bernier, A. Transforming young adult services: $A$ reader for our age (pp. 111-117). Chicago: ALA Neal-Schuman.

Korn, J. U. (2018). Equitable cities instead of smart cities: Race and racism within the race for smart cities. Journal of Civic Media, 1(1), 34-45.

Matsuda, M. J. (1989). Public response to racist speech: Considering the victim's story. Michigan Law Review, 87(8), 2320-2381.

Ladson-Billings, G. (1998). Just what is critical race theory and what's it doing in a nice field like education?. International Journal of Qualitative Studies in Education, 11(1), 7-24.

Larrick, N. (1965). The all white world of children's books. The Saturday Review. September 11, 63-65.

Low, J. (2016). Where is the diversity in publishing? The 2015 Diversity Baseline Survey results. Retrieved from http://blog. leeandlow.com/2016/01/26/ where-is-the-diversity-in-publishing-the-2015-diversity-baseline-survey-results/.

Mills, K. A., \& Godley, A. (2017). Race and racism in digital media: What can critical race theory contribute to research on techno-cultures?. In (Eds. Mills, A., Stornaiuolo, A., Smith, A., Zacher P. J.) Handbook of writing, literacies, and education in digital cultures. New York: Routledge.

Noble, S. U. (2018). Algorithms of oppression: How search engines reinforce racism. New York: NYU Press.

Olson, H. (1998). Mapping beyond Dewey's boundaries: Constructing classificator space for' marginalized knowledge domains. Library Trends, 47(2), 253-254.

Olson, H. (2001). The power to name: Representation in library catalogs. Signs 26 (3), 639-668.

Roberto, K. R. (Ed.). (2015). Radical cataloging: Essays at the front. Jefferson, NC: McFarland.

Samuel, K. (2015). Social media mechanisms: A change agent. In Starver Coombs \& Simon Collister (Eds.), Debates for the digital age: The good, the bad, and the ugly of our online world [2 volumes]. Prager/ABC-CLIO: CA.

Schlesselman-Tarango, G. (2017). Topographies of whiteness: Mapping whiteness in library and information science. Sacramento, CA: Library Juice Press.

Sweeney, M. E., Cooke, N. A., Villa-Nicholas, M., Roberto, K. R., \& Noble, S. U. (2014). Social justice in library and information science. iConference 2014 Proceedings. Retrieved from http://hdl.handle.net/2142/47390.

Sweeney, M. E., \& Brock, A. (2014). Critical informatics: New methods and practices. Proceedings of the American Society for Information Science and Technology, 51 (1), 1-8.

Taylor, E., Gillborn, D. \& Ladson-Billings, G. (Eds.). (2009). Foundations of critical race theory in education. New York, NY: Routledge.

Wolf, M. A., Jones, R., \& Gilbert, D. (2014). Leading in and beyond the library. Alliance for Excellent Education. Retrieved from https://all4ed.org/wp-content/uploads/2014/01/BeyondTheLibrary.pdf 